\title{
ANALISIS JEJARING SOSIAL UNTUK MANAJEMEN PENGELOLAAN PERBATASAN ANTARA NEGARA
}

\author{
Ady Muzwardi1)*, Adji Suradji Muhammad2)*, \\ Rolly Maulana Awangga ${ }^{3)^{*}}$, Arjuna Rizaldi4)* \\ 1,3Fakultas Ilmu Sosial dan Ilmu Politik Universitas Maritim Raja Ali Haji Tanjungpinang, \\ Kepulauan Riau Indonesia \\ 2Politeknik Pos, Bandung, Jawa Barat, Indonesia \\ ${ }^{4}$ Universitas Komputer Indonesia, Bandung, Jawa Barat, Indonesia \\ E-mail: 1ady muzwardi@umrah.ac.id, 2suradji@umrah.ac.id, 3awangga@poltekpos.ac.id, \\ 4arjuna@email.unikom.ac.id
}

\begin{abstract}
Abstrak
Kepulauan Riau merupakan provinsi yang berbatasan laut dengan banyak negara. Kondisi geostrategic tersebut menyebabkan pemerintah daerah di 5 Kabupaten/Kota yang berbatasan langsung negara tetangga membentuk Badan Pengelola Perbatasan. disisi lain Pemerintah Pusat memiliki lembaga-lembaga vertical yang berperan dalam mengelola kawasan perbatasan di Kepulauan Riau. Fungsi dan peran stakeholder perbatasan tersebut memiliki kelemahan dan kelebihan dalam mengelola perbatasan. Untuk mengkaji permasalahan dalam tata kelola perbatasan dan cara kolaborasi antar stakeholder pengelola perbatasan diperlukan analisa jejaring social melalui metode Analisis Stakeholders Pengelola Perbatasan, Analisis Derajat Node dan Derajat Rata-rata, serta Analisis Keterpusatan. Hasil dari kajian menunjukan masih belum terjadinya kolaborasi yang efektif antara Badan Nasional Pengelola Perbatasan dengan Satuan Kerja Perangkat Daerah (OPD) dimasing-masing Kabupaten/Kota dalam pengelolan kawasan perbatasan di Kepulauan Riau, hal ini disebabkan masih terdapat ego sektoral di masing-masing Stakeholders Pengelola Perbatasan. Kajian ini memiliki perbedaan dengan kajian perbatasan lainnya karena ruang lingkup wilayah penelitian berada diperbatasan laut dengan persebaran OPD Pengelolaan perbatasan Kabupaten/Kota yang jauh satu sama lainnya.
\end{abstract}

Kata kunci: pemerintahan kolaboratif, jejaring sosial, area perbatasan

\section{SOCIAL NETWORK ANALYSIS FOR BORDER MANAGEMENT BETWEEN COUNTRIES}

\begin{abstract}
The Riau Islands is one of the provinces bordering many countries. This geostrategic condition causes local governments in 5 districts / cities which directly borders neighboring countries is established a Border Management Agency. on the other hand, the central government has vertical institutions which plays a role in managing the border area in Riau Islands. The functions and roles of border stakeholders have weaknesses and strengths in managing borders. To examine problems in border governance and how to collaborate between stakeholders managing the border, Social network analysis is needed through the Border Management Stakeholders Analysis method, Analysis of Node
\end{abstract}


DOI: $10.34010 /$ agregasi.v8i2.3231

Available online at: https://ojs.unikom.ac.id/index.php/agregasi

Degrees and Average Degrees, and Centering Analysis. The results of the study show that there is still no effective collaboration between the National Border Management Agency with Regional Work Units in each Regency / City in the management of the border area in the Riau Islands this is because there is still sectoral ego in each of the Border Management Stakeholders. This study is different from other border studies because the scope of the research area is on the sea border with the distribution of OPD Management of District / City borders that are far from each other.

Keywords: collaborative governance, social networking, boarder area. 


\section{PENDAHULUAN}

Indonesia merupakan satu negara memiliki cakupan wilayah yang sangat luas dimana terdiri dari pulau dan laut yang mengelilinginya. Indonesia memiliki 17.499 pulau dengan wilayah lautnya seluas 5,8 juta $\mathrm{km} 2$ atau 2/3 wilayah Indonesia merupakan laut (Marsetio, 2014). Disamping itu Indonesia juga memiliki garis pantai yang membentang sepanjang 81.900 Km2. Ribuan pulau tersebar hampir diseluruh perairan Indonesia.

Indonesia berbatasan dengan 10 (sepuluh) negara lain yaitu Negara Malaysia, Singapura, Vietman, Filipina, Thailand, Kamboja, India, Papua New Guinea (PNG), Republik Palau, dan Australia. Wilayah perbatasan negara Indonesia sebagian besar dipisahkan oleh laut. Malaysia, Timor Leste, dan Papua New Guinea (PNG) merupakan tiga negara asing yang wilayahnya berbatasan langsung dengan daratan Indonesia.

Secara administratif, beberapa wilayah di Indonesia yang berbatasan langsung dengan negaara lain yaitu Provinsi Nangroe Aceh Darussalam (NAD), Provinsi Sumatera Utara, Provinsi Riau, Provinsi Kepulauan Riau, Provinsi Kalimantan Barat, Provinsi Kalimantan Timur, Provinsi Sulawesi Utara, Provinsi Maluku, Provinsi Maluku Utara, Provinsi Nusa Tenggara Timur (NTT), Provinsi Papua dan Provinsi Papua Barat (BNPP,
2011). Kawasan perbatasan tersebut berbatasan dengan darat, laut dan udara dengan negara lain dimana tersebar luas melalui berbagai tipologi alam yang beragam.

Perbatasan wilayah darat Indonesia tersebar pada 3 wilayah yaitu: Pulau Kalimantan perbatasan Indonesia dengan Malaysian, Papua perbatasan Indonesia dengan PNG dann Nusa Tenggara Timur perbatasan Indonesia dengan Timor Leste. Garis batas negara di Pulau Kalimantan antara RI-Malaysia terbentang sepanjang $2004 \mathrm{Km}$, di Papua antara RI-Papau Nugini (PNG) sepanjang 107 km, dan di Nusa Tenggara Timur antara RI-Timor Leste sepanjang kurang lebih $263,8 \mathrm{~km}$.

Sementara itu, kawasan perbatasan laut termasuk pulau-pulau kecil terluar berada di 7 (tujuh) kawasan yaitu: (1) Kawasan perbatasan laut RI dengan Negara Thailand/India/Malaysia termasuk 2 pulau kecil terluar yang ada di Provinsi Aceh dan Sumut; (2) Kawasan perbatasan laut RI dengan Negara Malaysia/Vietnam/Singapura termasuk 20 pulau kecil terluar yang ada di Provinsi Riau dan Kepulauan Riau; (3) Kawasan perbatasan laut RI dengan Negara Malaysia dan Filipina termasuk 18 pulau kecil terluar di Provinsi Kalimantan Timur, Sulawesi Tengah, dan Sulawesi Utara; (4) Kawasan perbatasan laut RI dengan negara Palau termasuk 8 pulau kecil terluar di Provinsi Maluku 
Utara, Papua Barat, dan Papua; (5) Kawasan perbatasan laut dengan Negara Timor Leste/Australia termasuk 20 pulau kecil terluar di Provinsi Maluku dan Papua; (6) Kawasan Perbatasan Laut RI dengan Negara Timor Leste termasuk 5 pulau kecil terluar di Provinsi NTT; dan (7) Kawasan Perbatasan Laut dengan laut lepas termasuk 19 pulau kecil terluar di Provinsi Aceh, Sumatera Utara, Sumatera Barat, Bengkulu. Lampung, Banten, Jawa Barat, Jawa Tengah, Jawa Timur, dan Nusa Tenggara Barat.

Berikut gambaran sebaran 10 (sepuluh) kawasan perbatasan yang ada di 12 (dua belas) Provinsi di Indonesia (BNPP, 2011).

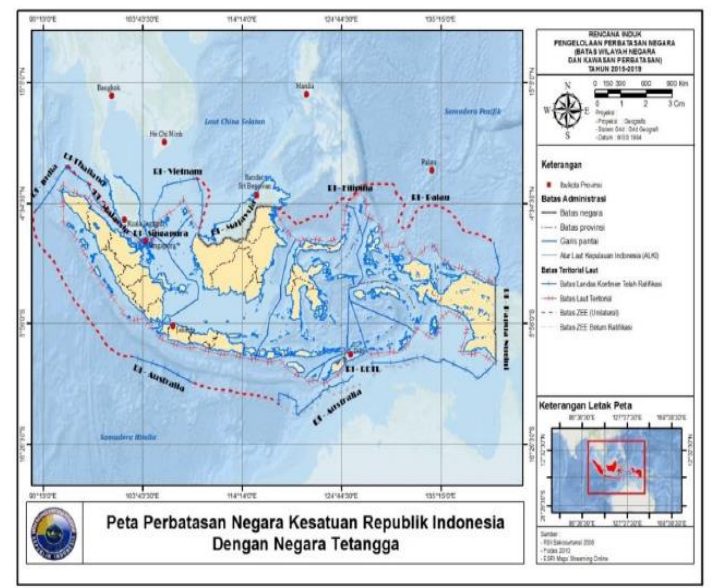

Sumber: Blue Print BNPP, 2015

Gambar 1. Peta Kawasan Perbatasan Indonesia

Provinsi Kepulauan Riau menjadi salah satu propinsi yang wilayahnya memiliki batas dengan negara lain. Kepulauan Riau merupakan propinsi yang memiliki wilayah geografis berupa kepulauan atau pulau-pulau yang berbatasan langsung dengan beberapa negara. Negara-negara tersebut yaitu negara Singapura, Malaysia, Vietnam serta Kamboja.

Undang-undang Nomor 25 tahun 2002 tentang Pembentukan Provinsi Kepulauan Riau, dijelaskan bahwa Kepulauan Riau memiliki luas wilayah $251.810,71 \mathrm{Km}^{2}$. Luas wilayah tersebut terdiri dari luas lautan sebesar 241.215,30 $\mathrm{Km}^{2}$ (95,79\%) sedangkan sisanya merupakan wilayah daratan yang memiliki luas $10.595,41 \mathrm{Km}^{2}(4,21$ $\%)$.

Sebagai kawasan kepulauan, Kepulauan Riau terdiri dari jumlah pulau yang banyak yaitu 2.408 pulau. Dari pulau-pulau tersebut, terdapat 19 buah pulau terluar yang berbatasan langsung dengan negara lain yang berada pada 5 (lima) kabupaten/kota di Provinsi Kepulauan Riau. Berdasarkan Keputusan Presiden Republik Indonesia Nomor 78 Tahun 2005 tentang Pengelolaan Pulaupulau Kecil Terluar yang menyatakan bahwa terdapat 19 pulau-pulau kecil terluar di Provinsi Kepulauan Riau sehingga berbatasan dengan beberapa negara. 


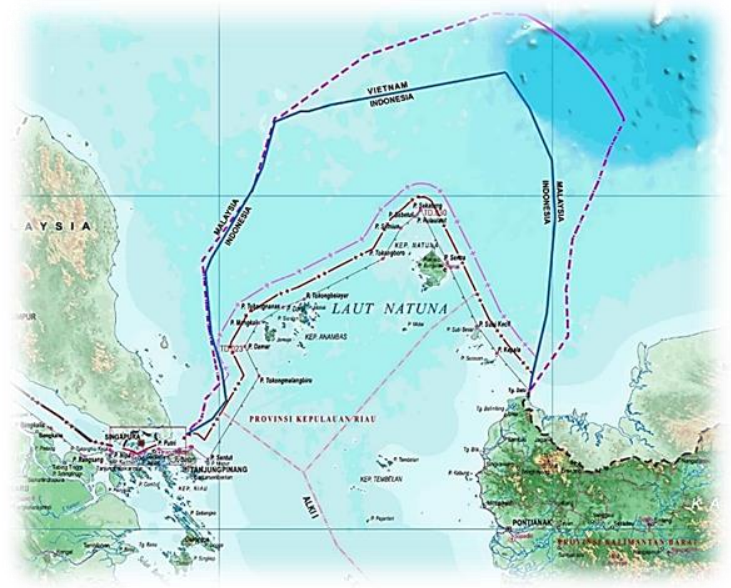

Sumber: Deputi Bidang Koordinasi SDM Kemenko Kemaritiman dan Investasi, 2020.

Gambar 2. Peta Kawasan Perbatasan Provinsi Kepulauan Riau

Wilayah Kepulauan Riau yang dibatasi oleh laut/perairan membuat kawasan ini komplek dalam pengelolaanya. Letak Kepulauan Riau yang berbatasan dengan banyak negara membuat kawasan ini menjadi sangat strategis bagi pemerintah pusat.

Wilayah perbatasan yang begitu strategis, maka pemerintah Indonesia telah mengeluarkan Peraturan Pemerintah Nomor 26 Tahun 2008 tentang Rencana Tata Ruang Wilayah Nasional. Dalam Peraturan Pemerintah tersebut dijelaskan bahwa wilayah perbatasan merupakan Pusat Kegiatan Strategis Nasional (PKSN) yang penataan ruangnya diprioritaskan.

Wilayah perbatasan menjadi prioritas bagi pemerintah pusat dikarenakan memiliki pengaruh besar terhadap kedaulatan negara dimana kedaulatan negara menjadi tonggak suatu negara. PKSN sendiri merupakan kawasan pedesaan di wilayah perbatasan yang menjadi kawasan perkotaan yang dibangun agar mampu mendorong pengembangan dari kawasan perbatasan tersebut. Pengembangan dari wilayah yang termasuk ke dalam PKSN dimaksudkan untuk memberikan pelayanan yang optimal terutama bagi peningkatan kesejahteraan masyarakat.

Secara umum, kondisi di kawasan perbatasan Kepulauan Riau mengalami berbagai permasalahan klasik. Beberapa permasalahan tersebut diantaranya adalah kualitas infrastruktur yang masih rendah, akses terhadap informasi yang terhambar, kondisi perekonomian yang masih tertinggal terutama terhadap kondisi di negara tetangga yang sangat jauh berbeda serta permasalahan lainnya yang memperlihatkan bahwa kawasan perbatasan di Kepulauan Riau sangat jauh tertinggal dan hanya menjadi halaman belakang negara yang terabaikan.

Landskap geografi yang dikeliling perairan, kawasan perbatasan di Kepulauan Riau memiliki permasalahan yang lebih besar ditengah masyarakat seperti terjadinya penyelundupan berbagai barang, begitu pula perompakan yang sering terjadi, adanya 
illegal fishing, serta illegal mining dan permasalahan lainnya.

Berbagai masalah tersebut saat ini juga telah-pun ada ditengah-tengah masyarakat mulai dari penyelundupan barang baik yang baru maupun yang bekas, hingga penyelundupan barang mewah dan bahkan narkotika. Hal ini sebagaimana yang diberitakan oleh Youtube yang mengatakan bahwa "Bea Cukai Kepulauan Riau menangkap KM Sapokat yang akan menyelundupkan ribuan karung berisi pakaian bekas asal Port Klang, Malaysia. Penangkapan dilakukan karena pengiriman barang tidak dilengkapi dokumen lengkap".

Dalam berita yang dibuat secara nasional oleh "Antara" pada bulan Oktober tahun 2013 juga telah memberitakan bahwa Bea Cukai telah berhasil menggagalkan penyelundupan Kamera sebanyak 30 koli atau setara dengan 500 unit seharga 6 milyar. Bahkan Kepulauan Riau juga tidak luput dari aktifitas penyelundupan narkotika dan obat-obatan terlarang, sebagaimana yang juga pernah diberitakan oleh Tribunnews.com dan dipublikasikan tanggal 24 Desember 2012 dengan judul berita "BC Tanjungpinang Batalkan Penyelundupan 3,4 kg Heroin".

Bahkan perompakan juga pernah terjadi beberapa kali di perairan Kepulauan Riau. Seperti diberitakan pada tahun 2014 telah terjadi aksi perompakan di Perairan Tanjung
Dato, Kepulauan Riau. Namun aksi ini berhasil digagalkan Satgas Western Fleet Quick Response (WFQR) Koarmabar. Tahun 2012, tepatnya pada bulan Desember juga telah terjadi perompakan Kapal KM Pelita dan juga Kapal Tongkang Olympus yang membawa BBM (Bahan Bakar Minyak) di perairan Selat Nenek, Kecamatan Moro Kabupaten Tanjung Balai Karimun.

Pada saat ditemukan kedua kapal ditemukan dalam keadaan kosong alias tanpa muatan. Komandan Pangkalan Angkatan Laut (Danlanal) Batam, Kolonel Laut (P) Nurhidayat mengatakan bahwa berdasarkan menifes, kapal tersebut bermuatan 150 ton solar dan 10 ton premium milik PT Dharma Karya Sentosa.

Melihat adanya berbagai aktifitas illegal ataupun aktifitas yang cenderung menuju kearah kriminal tersebut, maka diperlukan adanya upaya yang lebih serius dan terpadu. Pemerintah Provinsi Kepulauan Riau telah membentuk Badan Pengelola Perbatasan Kepulauan Riau.

Pembentukan BP Kepulauan Riau didasarkan pada Peraturan Daerah Nomor 5 Tahun 2011 tentang Organisasi Dan Tata Kerja Inspektorat, Badan Perencanaan Pembangunan Daerah, Lembaga Teknis Daerah, Satuan Polisi Pamong Praja Dan Lembaga Lain Provinsi Kepulauan Riau. Pasal 146 ayat (2) dinyatakan bahwa Lembaga Lain Provinsi Kepulauan Riau terdiri dari : a). 
Badan Pengelola Perbatasan Provinsi; b). Badan Ketahanan Pangan; c). Sekretariat KPID; dan d). Sekretariat Korpri.

Selanjutnya menurut Pasal 148 dikatakan bahwa Badan Pengelola Perbatasan (BPP) Provinsi mempunyai tugas merumuskan dan melaksanakan kebijakan teknis di bidang Pengelola Perbatasan serta melaksanakan tugas dekonsentrasi dan tugas pembantuan yang diserahkan oleh Gubernur sesuai dengan lingkup tugasnya.

Selain BPP Kepulauan Riau, terdapat 4 (empat) Kabupaten dan 1 (satu) Kota yang memiliki Struktur Organisasi dan Tata Kerja (SOTK) yang menjalankan tugas-tugas Badan Nasional Pengelola Perbatasann atau BNPP dengan nama yang berbeda-beda. Ke-empat kabupaten tersebut adalah Kabupaten Bintan, Kabupaten Karimun, Kabupaten Natuna dan Kabupaten Kepulauan Anambas. Sedangkan satu-satunya kota yang memiliki SOTK yang mengelola perbatasan adalah Kota Batam yang digabung dengan Pertanahan.

BPP Kepulauan Riau sendiri telah menyusun dokumen Rencana Strategis Badan Pengelola Perbatasan Provinsi Kepulauan Riau tahun 2010-2015. Dalam dokumen tersebut BPP Provinsi Kepulauan Riau telah melakukan identifikasi berbagai permasalahan di Provinsi Kepulauan Riau baik yang berkaitan dengan permasalahan batas antar negara hingga persoalan wawasan kebangsaan.

Berdasarkan dokumen Renstra Provinsi Kepulauan Riau tersebut di atas, terdapat beberapa isu strategis yang telah teridentifikasi yang dituangkan dalam bab III dimana ditemukan beberapa permasalahan yang berhasil diidentifikasi dalam 5 (lima) kelompok masalah besar.

Kelima permasalahan tersebut adalah; a) Konflik batas negara, b) Lemahnya kelembagaan pemerintah dalam mengelola kawasan perbatasan, c) Pola pembangunan kawasan perbatasan, d) Sumberdaya Manusia dan Sumberdaya Alam dan e) Penurunan wawasan kebangsaan.

Terkait dengan permasalahan kedua yaitu "lemahnya kelembagaan pemerintah dalam mengelola kawasan perbatasan", BP Kepulauan Riau juga telah melakukan inventarisasi masalah kedalam 3 (tiga) isu utama yaitu; 1) Isu kawasan perbatasan belum menjadi agenda pembangunan prioritas yang ditangani secara komprehensif dan terpadu; 2) Meningkatnya aktivitasaktivitas ilegal di wilayah perbatasan, dan 3) Lemahnya penegakan hukum terhadap para pencuri kayu (illegal logger), penyelundupan barang, penjualan manusia (human trafficking), pembajakan dan perompakan kapal, penyelundupan senjata, penyelundupan manusia (seperti tenaga kerja, bayi, dan 
wanita), maupun pencurian ikan, terutama pada grey area.

Berbagai permasalahan diatas seharusnya dapat dengan mudah diselesaikan dengan pendekatan Collaborative antar lembaga negara yang tertuang dalam Peraturan Presiden Nomor 12 Tahun 2010 tentang Badan Nasional Pengelola Perbatasan dan diperkuat dengan Undang-undang No 23 tahun 2014 tentang Pemerintahan Daerah. Dengan ketersediaan regulasi yang memungkinkan keterlibatan stake holder baik di Pusat maupun di Daerah diharapkan permasalahanpermasalahan yang ada di kawasan perbatasan dapat dengan efektif diselesaikan. Kajian ini perlu dilakukan untuk menganalisa hambatan pengelolaan perbatasan di Indonesia secara umum dan Kepulauan Riau secara khusus.

\section{METODE}

\section{Jenis Penelitian}

Penelitian ini menggunakan penelitian Deskriptif dengan pendekatan Kuantitatif. Nana Sudjana (2004) mengatakan bahwa Deskriptif Kuantitatif adalah "Metode penelitian deskriptif dengan pendekatan secara kuantitatif digunakan apabila bertujuan untuk mendeskripsikan atau menjelaskan peristiwa atau suatu kejadian yang terjadi pada saat sekarang dalam bentuk angka-angka yang bermakna". Tujuan pengguna metode Deskriptif Kuantitatif ini untuk mengukur hubungan variabel kolaborasi dengan melihat berbagai factor yang faktor-faktor yang mendukung dan menghambat analisis jejaring sosial dalam manajemen pengelolaan kawasan perbatasan terutama di Kepulauan Riau.

\section{Sumber Data}

Data primer serta data sekunder dilakukan sebagai sumber data dalam penelitian yang dibuat. Kedua data tersebut digunakan untuk menganalisa praktek kolaborasi dan menganalisa regulasi pendukung kolaborasi sehingga didapat keterkaitan dan penyimpangan antara praktek dan regulasi yang ada.

1) Data primer berasal dari angket, wawancara mendalam dan observasi. Guna mempermudah dalam pengisian angket, maka angket dibuat dengan menggunakan aplikasi "google form". Disamping data primer berupa angket, data primer selanjutnya diperoleh melalui wawancara mendalam. Wawancara mendalam (deepth interview) dilakukan kepada pihak-pihak yang memiliki otoritas dalam mengelola kawasan perbatasan. Dengan demikian informasi satu dengan informasi yang lain akan saling melengkapi guna mengurai permasalahan yang terjadi di daerah perbatasan. Data berupa 
angket dan deepth interview diperoleh dari pejabat berwenang di masing-masing institusi pengelola perbatasan di wilayah Kepulauan Riau.

2) Data sekunder berfungsi sebagai pelengkap informasi. Data sekunder diperoleh melalui arsip penting yang ada dimasing-masing lembaga yang terlibat dalam pengelolaan kawasan perbatasan, Momorandum of Understanding (MOU), Undangundang (UU), Peraturan Pemerintah (PP), Peraturan Presiden (Perpres), Keputusan Presiden (Kepres), Peraturan Menteri (Permen) dan data lain yang memiliki keterkaitan dengan pengelolaan kawasan perbatasan di Kepulaauan Riau.

\section{Responden}

Responden dalam kajian ini berjumlah 23 orang yang berasal dari unsur lembaga teknis yang berkaitan dengan pengelolaan perbatasan yang terdiri dari 17 lembaga vertical (Kementerian dan non Kementerian) dan 6 lembaga daerah (Badan Pengelola perbatasan daerah). Salah satu pertanyaan yang diberikan ke responden terkait kebijakan yang disepakati bersama telah terlaksana sesuai dengan yang direncanakan.

\section{Analisis Data}

analisis hubungan sosial (SNA) merupakan pemetaan dan sekaligus untuk memastikan hubungan dan aliran hubungan antar seseorang, kelompok, organisasi, komputer maupun informasi atau pengetahuan lainya dalam sebuah perkumpulan. SNA dipilih oleh peneliti bertujuan untuk mengetahui pola jaringan atau Network Overview antar stakeholder. Untuk mempermudah dalam melakukan Analisa, maka Lembaga disebut "node" yang bertujuan untuk mengurai rangkaian hubungan antar stakeholder. Untuk memvisualisasikan dan mengeksplorasi semua jenis grafik dan jaringan dalam SNA diperlukan statistik Gephi sebagai sarana untuk mempermudah dalam memahami pola jaringan. statistik Gephi 0.9.1 yang digunakan untuk menganalisa kajian ini diantaranya;

1) Derajat Node (Average Degree) memiliki peran kunci dalam menganalisa sebuah jaringan melalui perhitungan derajatnya.

2) Jarak, Diameter dan Average Path Length. Secara fisik node dikelompokkan kedalam kategori berdasarkan jarak (distance) yang jelas.

3) Betweenness centrality, yaitu suatu ukuran yang digunakan untuk melihat peran dari sebuah node sehingga menjadi bottleneck. Pada node sendiri menjadi sesuatu yang penting apabila berubah menjadi sebuah communication bottleneck. 


\section{HASIL DAN PEMBAHASAN}

\section{Analisis Stakeholders Pengelola Perbatasan}

Negara Indonesia diakui dunia sebagai archipelagic state atau Negara Kepulauan, Hal ini ditandai dengan ditandatanganinya Konvensi Perserikatan Bangsa-Bangsa tentang hukum laut yaitu United Nation Convention on the Law Of Sea (UNCLOS '82) mebuat Indonesia meratifikasi konvensi ini dengan Undang-Undang Republik Indonesia Nomor 17 tahun 1985.

Sebagai negara kepulauan, Indonesia mempunyai jumlah pulau sebanyak 17.508 buah. Jumlah pulau tersebut merupakan hasil perhitungan yang dilakukan oleh Jawatan HidroOseanografi (Janhidros) TNI AL pada tahun 1982.

Kawasan Perbatasan Indonesia dengan negara tetangga berada di 12 (dua belas) Provinsi yaitu NAD, Sumatera Utara, Riau, Kepulauan Riau, Kalimantan Barat, Kalimantan Timur, Sulawesi Utara, Maluku, Maluku Utara, Nusa Tenggara Timur (NTT), Papua dan Papua Barat.

Pulau-pulau yang dalam garis terdepan/terluar tersebut mempunyai peranan yang sangat strategis terutama dalam mempertahankan keamanan negara melalui kedaulatan negara. Pulau yang memiliki batas dengan negara lain mempunyai potensi sumber daya yang cukup potensial. Apabila mampu dikembangkan akan menjadi kawasan yang berkembang dengan baik sehingga tidak akan tertinggal dengan negara tetangganya.

Meskipun menyimpan potensi yang cukup besar, namun faktanya kondisi ekonomi masyarakat terutama di kawasan yang berbatasan dengan negara tetangga selalu tertinggal dengan daerah lainnya apalagi dengan wilayah negara yang berbatasan. Dari 199 kabupaten yang masuk dalam kategori "tertinggal" di Indonesia pada tahun 2007, sebanyak 34 kabupaten terdapat berada di kawasan perbatasan dengan klasifikasi agak tertinggal, hingga sangat parah ketertinggalannya.

Ketertinggalan ini disebabkan antara lain; rendahnya aksesibilitas transportasi maupun jalan yang menghubungkan antar kawasan perbatasan dengan pusat pemerintahan; informasi atas pembangunan masih terbatas; terbatasnya sarana dan prasarana ekonomi seperti, listrik, transportasi, energi, irigasi dan perdagangan. Dari berbagai keterbatasan sarana dan prasarana tersebut berimplikasi pada minimnya investasi yang masuk.

Selain beberapa hal tersebut diatas, kesenjangan orientasi pembangunan yang dilakukan oleh Pemerintah Pusat antara kawasan perbatasan dengan Kawasan Indonesia tengah terlihat jelas. Kesenjangan ini selanjutnya dapat 
memicu orientasi perekonomian masyarakat yang tinggal diperbatasan. Untuk itu pemerintah pusat dapat membuat rencana strategis dalam mempercepat pembangunan di wilayah perbatasan dengan meningkatkan keamanan wilayahnya, meningkatkan kesejahteraan masyarakat, serta kelestarian dari lingkungan mereka.

Untuk mempercepat ketertinggalan dalam pembangunan kawasan perbatasan, pemerintah telah membentuk Badan Nasional Pengelolaan Perbatasan atau BNPP. BNPP diketuai oleh Menteri Dalam Negeri dengan beranggotakan 15 (lima belas) lembaga Kementrian dan lembaga nonkementrian. Disamping ada 16 (enam belas) Kementrian dan non-Kementrian yang berfungsi sebagai Ketua dan Anggota BNPP, terdapat 3 (tiga) Menteri Koordinator yang menjadi Pengarah dari BNPP.

Banyaknya Kementerian maupun Lembaga non-Kementerian terlibat dalam BNPP tersebut diharapkan dapat mengakselerasi pembangunan kawasan perbatasan. Akselerasi dalam pembangunan kawasan perbatasan menjadi target utama sehingga kawasan perbatasan Indonesia dapat sejajar dengan kawasan perbatasan dari negara tetangga.

Berikut daftar stakeholders yang terlibat dalam pengelolaan Kawasan perbatasan Antar Negara mulai dari tingkat pusat yang selanjutnya diberi kode BN hingga tingkat daerah yang diberi kode BD.

\begin{tabular}{|c|c|c|c|}
\hline NO & KODE & INSTITUSI & $\begin{array}{c}\text { DASAR } \\
\text { HUKUM }\end{array}$ \\
\hline 1 & BN 1 & $\begin{array}{c}\text { Kementria } \\
\text { n Dalam } \\
\text { Negeri }\end{array}$ & $\begin{array}{c}\text { Perpres } \\
12 / 2010\end{array}$ \\
\hline 2 & BN 2 & $\begin{array}{c}\text { Kementria } \\
\text { n Luar } \\
\text { Negeri }\end{array}$ & $\begin{array}{c}\text { Perpres } \\
12 / 2011\end{array}$ \\
\hline 3 & BN 3 & $\begin{array}{c}\text { Kementria } \\
\text { n } \\
\text { Pertahana } \\
n\end{array}$ & $\begin{array}{c}\text { Perpres } \\
12 / 2011\end{array}$ \\
\hline 4 & BN 4 & $\begin{array}{c}\text { Kementria } \\
\text { n Hukum } \\
\text { dan Hak } \\
\text { Asasi } \\
\text { Manusia }\end{array}$ & $\begin{array}{c}\text { Perpres } \\
12 / 2011\end{array}$ \\
\hline 5 & BN 5 & $\begin{array}{c}\text { Kementria } \\
\text { n } \\
\text { Keuangan }\end{array}$ & $\begin{array}{c}\text { Perpres } \\
12 / 2011\end{array}$ \\
\hline 6 & BN 6 & $\begin{array}{c}\text { Kementria } \\
\mathrm{n} \\
\text { Pekerjaan } \\
\text { Umum }\end{array}$ & $\begin{array}{c}\text { Perpres } \\
12 / 2011\end{array}$ \\
\hline 7 & BN 7 & $\begin{array}{c}\text { Kementria } \\
n \\
\text { Perhubung } \\
\text { an } \\
\end{array}$ & $\begin{array}{c}\text { Perpres } \\
12 / 2011\end{array}$ \\
\hline 8 & BN 8 & $\begin{array}{c}\text { Kementria } \\
\text { n } \\
\text { Kehutanan }\end{array}$ & $\begin{array}{c}\text { Perpres } \\
12 / 2011\end{array}$ \\
\hline 9 & BN 9 & $\begin{array}{c}\text { Kementria } \\
\text { n Kelautan } \\
\text { dan } \\
\text { Perikanan } \\
\end{array}$ & $\begin{array}{c}\text { Perpres } \\
12 / 2011\end{array}$ \\
\hline 10 & BN 10 & $\begin{array}{c}\text { Kementria } \\
\mathrm{n} \\
\text { Perencana } \\
\text { an } \\
\text { Pembangu } \\
\text { nan } \\
\text { Nasional/ } \\
\text { Kepala } \\
\text { Badan } \\
\text { Perencana } \\
\end{array}$ & $\begin{array}{c}\text { Perpres } \\
12 / 2011\end{array}$ \\
\hline
\end{tabular}


DOI: $10.34010 /$ agregasi.v8i2.3231

Available online at: https://ojs.unikom.ac.id/index.php/agregasi

\begin{tabular}{|c|c|c|c|}
\hline NO & KODE & INSTITUSI & $\begin{array}{c}\text { DASAR } \\
\text { HUKUM }\end{array}$ \\
\hline & & $\begin{array}{c}\text { an } \\
\text { Pembangu } \\
\text { nan } \\
\text { Nasional } \\
\end{array}$ & \\
\hline 11 & BN 11 & $\begin{array}{c}\text { Kementria } \\
\mathrm{n} \\
\text { Pembangu } \\
\text { nan } \\
\text { Daerah } \\
\text { Tertinggal }\end{array}$ & $\begin{array}{c}\text { Perpres } \\
12 / 2011\end{array}$ \\
\hline 12 & BN 12 & $\begin{array}{c}\text { Panglima } \\
\text { Tentara } \\
\text { Nasional } \\
\text { Indonesia } \\
\end{array}$ & $\begin{array}{c}\text { Perpres } \\
12 / 2011\end{array}$ \\
\hline 13 & BN 13 & $\begin{array}{c}\text { Kepolisian } \\
\text { Negara } \\
\text { Republik } \\
\text { Indonesia } \\
\end{array}$ & $\begin{array}{c}\text { Perpres } \\
12 / 2011\end{array}$ \\
\hline 14 & BN 14 & $\begin{array}{l}\text { Badan } \\
\text { Intelijen } \\
\text { Negara }\end{array}$ & $\begin{array}{c}\text { Perpres } \\
12 / 2011\end{array}$ \\
\hline 15 & BN 15 & $\begin{array}{c}\text { Badan } \\
\text { Koordinasi } \\
\text { Survei dan } \\
\text { Pemetaan } \\
\text { Nasional/ } \\
\text { BIG Badan } \\
\text { Informasi } \\
\text { Geopasial }\end{array}$ & $\begin{array}{c}\text { Perpres } \\
12 / 2011\end{array}$ \\
\hline 16 & BN 16 & $\begin{array}{c}\text { Gubernur } \\
\text { Provinsi } \\
\text { Kepulauan } \\
\text { Riau } \\
\end{array}$ & $\begin{array}{c}\text { Perpres } \\
12 / 2011\end{array}$ \\
\hline 17 & BN 17 & $\begin{array}{l}\text { BAKAMLA } \\
\text { (Badan } \\
\text { Keamanan } \\
\text { Laut) } \\
\text { Perpres }\end{array}$ & $\begin{array}{c}\text { Perpres } \\
178 \\
\text { Tahun } \\
2014\end{array}$ \\
\hline 18 & BD 1 & $\begin{array}{c}\text { BP } \\
\text { Provinsi } \\
\text { Kepulauan } \\
\text { Riau }\end{array}$ & $\begin{array}{c}\text { UU } \\
23 / 2004\end{array}$ \\
\hline 19 & BD 6 & $\begin{array}{c}\text { BPP dan } \\
\text { Pertanaha } \\
\text { n Kota } \\
\text { Batam } \\
\end{array}$ & $\begin{array}{c}\text { UU } \\
23 / 2004\end{array}$ \\
\hline
\end{tabular}

\begin{tabular}{|c|c|c|c|}
\hline NO & KODE & INSTITUSI & $\begin{array}{c}\text { DASAR } \\
\text { HUKUM }\end{array}$ \\
\hline 20 & BD 7 & $\begin{array}{c}\text { BPP } \\
\text { Bintan }\end{array}$ & $\begin{array}{c}\text { UU } \\
23 / 2004\end{array}$ \\
\hline 21 & BD 8 & $\begin{array}{c}\text { BPP } \\
\text { Natuna }\end{array}$ & $\begin{array}{c}\text { UU } \\
23 / 2004\end{array}$ \\
\hline 22 & BD 9 & $\begin{array}{c}\text { BPP } \\
\text { Karimun }\end{array}$ & $\begin{array}{c}\text { UU } \\
23 / 2004\end{array}$ \\
\hline 23 & BD 10 & $\begin{array}{c}\text { BPP } \\
\text { Kepulauan } \\
\text { Anambas }\end{array}$ & $\begin{array}{c}\text { UU } \\
23 / 2004\end{array}$ \\
\hline
\end{tabular}

Sumber: Data Olahan, 2016

Dari tabulasi tersebut diatas dapat diketahui bahwa BNPP dibentuk pada tahun 2010 berdasarkan Peraturan Presiden Nomor 12 Tahun 2010. Menyadari bahwa BNPP memiliki keterbatasan, maka Presiden selang setahun kemudian, melibatkan Kementerian maupun Lembaga NonKementerian yang dianggap memiliki keterkaitan dengan tugas dan fungsi BNPP dilibatkan secara legal dalam keanggotaan BNPP.

Sedangkan untuk daerah-daerah yang berbatasan dengan negara tetangga, berdasarkan kewenangan yang dimiliki merujuk pada Undang-undang Nomor 23 tahun 2014 tentang Pemerintahan Daerah juga telah membentuk Satuan Kerja Perangkat Daerah yang bertugas untuk menjalankan kewenangan Kepala Daerah dalam hal mengelola perbatasan dengan negara tetangga.

\section{Analisis Derajat Node dan Derajat Rata-rata (Average Degree). \\ Dalam melakukan Analisa menggunakan Social Networking}


Analysis atau SNA, Lembaga-lembaga atau stakeholders yang terlibat dalam pengelolaan perbatasan diberi kode atau sebutan "node".

Node adalah sebutan lain dari pihakpihak yang terlibat dalam tema tertentu dalam hal ini adalah pengelolaan perbatasan. Masing-masing memiliki tingkat atau derajat yang berbeda-beda sesuai dengan kewenangan yang dimiliki. Derajat node tersebut memiliki peran kunci dalam sebuah jaringan kerja.

Derajat dari node dinotasikan sebagai jumlah link yang insiden dengan node tersebut atau dengan kata lain derajat adalah banyaknya node yang berdampingan atau berbatasan (adjacent) dengan node itu. Misalkan $\mathrm{n}$ adalah jumlah node dalam suatu jaringan tak berarah maka jumlah total dari link L dapat diekspresikan sebagai jumlah derajat.

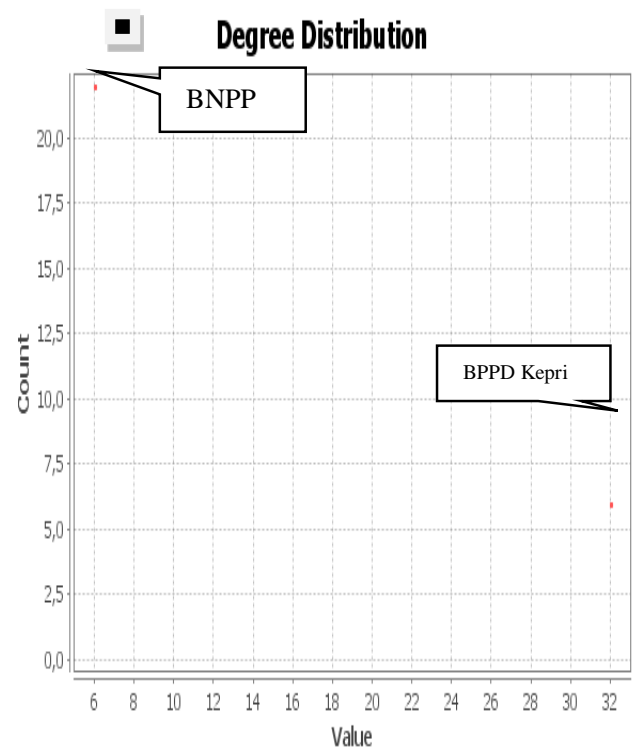

Sumber: Gephi.09.1, 2016

Gambar 2. Degree Distribution

Dari gambar diatas dapat diketahui bahwa terdapat 1 node (stakeholders) yang memiliki derajat tertinggi dan 1 node yang memiliki derajat rendah. Node dengan derajat tinggi ada pada BNPP dan derajat terendah ada di BPP Provinsi Kepulauan Riau. BNPP memiiki derajat yang tinggi dalam pengelolaan perbatasan karena BNPP memiliki kewenangan dalam merencanakan pengelolaan perbatasan. Sedangkan Kementerian dan Lembaga Non Kementrian tidak memiliki kewenangan dalam melakukan perencanaan pembangunan perbatasan. Meskipun mereka tidak memiliki kewenangan dalam pengelolaan perbatasan, namunmereka (kementerian dan Lembaga Non-Kementerian tersebut 
memiliki kewenangan dalam penganggaran dan pelaksanaan.

Sedangkan BPPD Provinsi Kepulauan Riau menjadi Lembaga yang dilematis. Karena posisi Provinsi adalah perwakilan pemerintah pusat di daerah (merujuk pada UU No 32 tahun 2014), maka pemerintah provinsi tidak memiliki kewenangan dalam hal merencanakan pengelolan perbatasan karena sudah dilakukan oleh BNPP. Sebagai manifestasi pemerintah pusat. Dalam hal melakukan eksekusi perencaan program BPPD Provinsi juga tidak memiliki kewenangan karena eksekusi dilakukan oleh pemerintah Kabupaten/Kota yang memiliki perbatasan dengan negara tetangga.

\section{Analisis Keterpusatan.}

Centrality atau derajat keterpusatan adalah tingkat keterpusatan dari seluruh jaringan yang ada. Centrality digunakan untuk mengetahui bobot suatu node/ lembaga dalam melaksanakan tugas dan fungsinya. Dengan mengetahui tingkat keterpusatan tersebut secara kuantitatif maka kita dapat mengetahui lebih akurat lembaga/node mana yang paling berpengaruh diantara node-node yang lain. Centrality juga memberikan petunjuk kepada kita node/lembaga mana yang tentu saja dianggap paling "penting" dalam sebuah jejaring/graf.

Dalam aplikasi web misalnya, kita dapat mengasumsikan bahwa setiap node dalam graf mewakili sebuah laman, sedangkan busur/garis (edge) yang terbentuk antar dua node mewakili ada atau tidaknya tautan. Berikut Graph yang terbentuk dalam collaborative governance yang melibatkan 23 lembaga pemerintah.

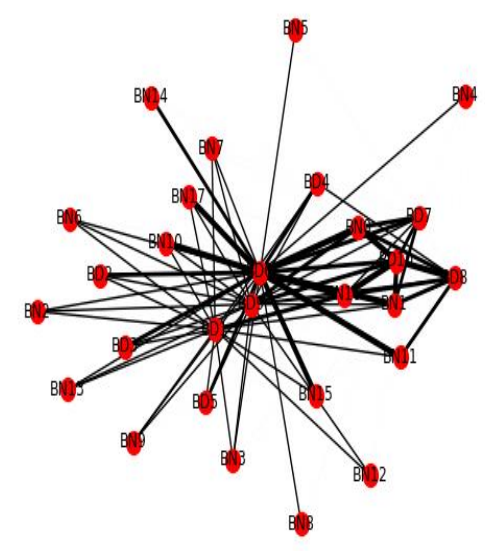

Gambar 3. Graph yang terbentuk dalam CG Pengelolaan Kawasan Perbatasan di Kepulauan Riau. Sumber: Gephi 09.1, 2016

Selanjutnya dari gambar edge jejaring yang ada diatas kita dapat mengetahui tingkat keterpusatan /centrality.

Definisi yang paling sederhana dari sentralitas node adalah bahwa sebuah node/lembaga menjadi sentral haruslah node tersebut merupakan lembaga yang paling aktif atau node yang memiliki ikatan paling banyak dengan node lain dalam jaringan.

Ada empat ukuran dalam sentralitas yang digunakan secara luas dalam 
analisis jaringan yaitu: derajat sentralitas (degree centrality), kedekatan (closeness), dan keantaraan (betweenness). Berikut akan dijelaskan satu persatu bagian dari centrality.

Jika dilihat dari graf tersebut terlihat bahwa node dengan kode BD6, BD7, BD8, BD9, BD10 dan BD1 memiliki tingkat keterpusatan lebih tinggi dibandingkan dengan BN (Kementerian atau Lembaga Non Kementerian ditingkat Pusat). BD merupakan lembaga daerah yang dibentuk oleh pemerintah daerah setempat dengan tugas pokok dan fungsi mengelola perbatasan. Sedangkan BN adalah Lembaga ditingkat pusat baik Kementerian maupun Lembaga NonKementrian.

Analisis Derajat Keterpusatan.

Degree centarality merupakan jumlah koneksi atau hubungan yang dimiliki oleh sebuah node. Derajat keterpusatan adalah jumlah hubungan simpul ke simpul lain secara langsung. Derajat keterpusatan pada analisis jejaring sosial digunakan sebagai simbul tingkat "popularitas" atau "keselebritian" seseorang/ Lembaga/ node.

Makin tinggi derajat suatu simpul, maka makin banyak kenalan individu yang direpresentasikan simpul tersebut. Degree centrality merupakan bentuk hubungan antar lembaga yang memiliki kewenangan dalam mengelola wilayah perbatasan yang ada di Kepulauan Riau.
Berikut gambar yang menunjukkan tingkat kerapatan hubungan antar node. Terlihat bahwa BTH (BPPP Kota Batam) memiliki derajat keterpusatan yang paling tinggi dibandingkan dengan nodenode lainya.

Tabel 1. Derajat Keterpusatan Lembagalembaga Pengelola Perbatasan di Kepulauan Riau

\begin{tabular}{|c|c|c|c|}
\hline NO & NODE & EDGE & $\begin{array}{c}\text { DEGREE } \\
\text { CENTRALITY }\end{array}$ \\
\hline (1) & (2) & (3) & $(4)$ \\
\hline 1 & BN8 & 1 & 0.22 \\
\hline 2 & BN14 & 2 & 0.22 \\
\hline 3 & BN11 & 3 & 0.22 \\
\hline 4 & BN17 & 4 & 0.22 \\
\hline 5 & BD6 & 5 & 1.0 \\
\hline 6 & BN4 & 6 & 0.22 \\
\hline 7 & BD4 & 7 & 0.22 \\
\hline 8 & BN15 & 8 & 0.22 \\
\hline 9 & BN3 & 9 & 0.22 \\
\hline 10 & BN9 & 10 & 0.22 \\
\hline 11 & BN2 & 11 & 0.22 \\
\hline 12 & BN5 & 12 & 0.22 \\
\hline 13 & BN13 & 13 & 0.22 \\
\hline 14 & BN12 & 14 & 0.22 \\
\hline 15 & BNO & 15 & 0.22 \\
\hline 16 & BD2 & 16 & 0.22 \\
\hline 17 & BD3 & 17 & 0.22 \\
\hline 18 & BN10 & 18 & 0.22 \\
\hline 19 & BD7 & 19 & 1.0 \\
\hline 20 & BN16 & 20 & 0.22 \\
\hline 21 & BD8 & 21 & 1.0 \\
\hline 22 & BD5 & 22 & 0.22 \\
\hline 23 & BN1 & 23 & 0.22 \\
\hline 24 & BN7 & 24 & 0.22 \\
\hline 25 & BD9 & 25 & 1.0 \\
\hline 26 & BD10 & 26 & 1.0 \\
\hline
\end{tabular}




\begin{tabular}{|c|c|c|c|}
\hline NO & NODE & EDGE & $\begin{array}{c}\text { DEGREE } \\
\text { CENTRALITY }\end{array}$ \\
\hline$(1)$ & $(2)$ & $(3)$ & $(4)$ \\
\hline 27 & BN6 & 27 & 0.22 \\
\hline 28 & BD1 & 28 & 1.0 \\
\hline \hline
\end{tabular}

Sumber; Data Olahan 2016.

Dari tabel diatas (degree centrality), terlihat bahwa BD 6 (Badan Pengelola Perbatasan dan Pertanahan Batam), BD 7, BD 8, BD 9 dan BD 10 dan BD 1 memiliki tingkat kerapatan hubungan yang lebih tinggi dibandingkan dengan edge yang lain sebesar 1.0. Sedangkan hubungan yang terjadi antar lembagalembaga lain yang ada ditingkat Pusat memiliki tingkat hubungan yang lebih rendah yaitu sebesar 0.22. Hal ini menunjukkan bahwa Badan Pengelola Perbatasan di Daerah memiliki hubungan yang lebih kuat dengan sesama Badan pengelola Perbatasan di daerah jika dibandingkan dengan Badan pengelola Perbatasan di tingkat Nasional/Pusat. Menurut Bodin (Baird et al., 2016) kepadatan jaringan yang relatif tinggi mampu meningkatkan potensi tindakan kolektif dan kolaborasi. Hal ini disebabkan karena jaringan yang terhubung mampu memfasilitasi komunikasi, saling percaya, dan saling membantu untuk mencegah atau mengelola konflik.

Kepadatan yang tinggi dari sebuah jaringan juga mungkin memiliki beberapa efek samping. Diibaratkan jika ada seorang aktor/artis dengan terlalu banyak ikatan, maka ia merasa memiliki kewajiban untuk menyenangkan semua atau sebagian besar mitra kolaboratifnya.

Hal ini dapat mengurangi kemungkinan aktor/artis tersebut untuk bertindak dan bahkan memperlambat kemajuan, sehingga terjadi 'kelelahan kemitraan. Lebih-lebih, jalinan hubungan kolaboratif dapat mengurangi transparansi dan akuntabilitas. Selain itu, jaringan padat menyiratkan relatif sedikit kontak dengan outsiders yang mungkin memiliki poin yang berbeda pandangan. Hal ini dapat mengurangi kemampuan untuk berinovasi (Baird et al., 2016).

Jika digambarkan dalam bentuk graph maka hubungan yang terjalin antar lembaga daerah dan lembaga ditingkat pusat terlihat seperti gambar dibawah ini. Gambar tersebut memperjelas bahwa hubungan/jaringan yang terbentuk oleh lembaga pengelola di tingkat daerah lebih banyak jika dibandingkan dengan jaringan yang dibentuk oleh lembaga yang memiliki kewenangan mengelola perbatasan di tingkat nasional. 


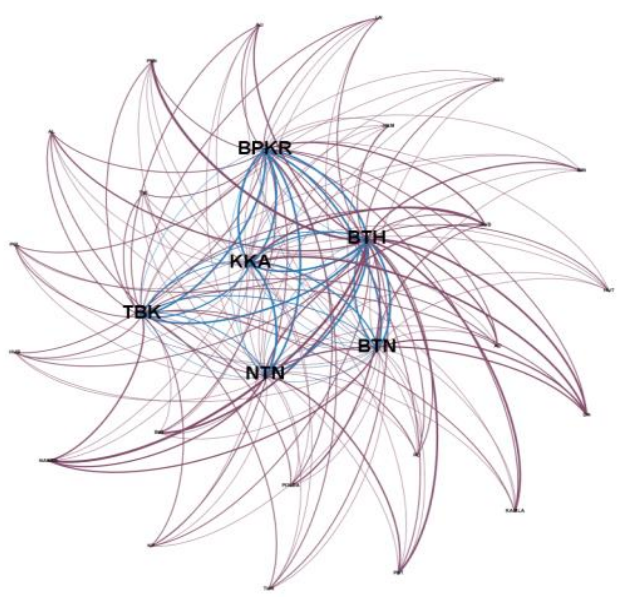

Diagram 1. Degree Centrality Lembaga Pengelola Perbatasan Sumber: SNA 09.1, 2016

Berikut akan diuraikan lebih detail dari derajat keterpusatan;

\section{a) Closeness centrality.}

Closeness Centrality atau kedekatan antar node merupakan jarak terpendek terhadap node-node yang lain. Contohnya dalam pemilihan lokasi yang dipandang cocok untuk membangun sebuah mall/supermarket dalam suatu kota dengan tujuan untuk meminimalkan jarak dengan para konsumen. Jarak tersebut menggambarkan kedekatan dari sebuah node dengan node lainnya.

Jarak yang semakin dekat maka menunjukkan keterhubungan yang tinggi antara lembaga satu dengan lembaga yang lainnya. Berdasarkan hal tersebut, analoginya adalah tipe orang "gaul" yang kenal dengan semua orang akan memiliki pengaruh yang lebih besar karena dapat menyebarkan informasi lebih cepat tanpa perlu perantara pihak ketiga.

Sentralitas Kedekatan (Closeness Centrality) menunjukkan kedekatan sebuah simpul dengan simpul-simpul lainya. Derajat individu/institusi dalam jejaring sosial diartikan sebagai banyak anggota lain yang dikenal oleh suatu individu, namun individu tersebut belum tentu dekat dan mengetahui detail anggota lain.

Tabel 2. Derajat Closenee Centrality

\begin{tabular}{|c|c|c|c|}
\hline No & Node & Edge & $\begin{array}{c}\text { Closeness } \\
\text { Centrality }\end{array}$ \\
\hline$(1)$ & $(2)$ & $(3)$ & $(4)$ \\
\hline 1 & BN8 & 1 & 0.5625 \\
\hline 2 & BN14 & 2 & 0.5625 \\
\hline 3 & BN11 & 3 & 0.5625 \\
\hline 4 & BN17 & 4 & 0.5625 \\
\hline 5 & BD6 & 5 & 1.0 \\
\hline 6 & BN4 & 6 & 0.5625 \\
\hline 7 & BD4 & 7 & 0.5625 \\
\hline 8 & BN15 & 8 & 0.5625 \\
\hline 9 & BN3 & 9 & 0.5625 \\
\hline 10 & BN9 & 10 & 0.5625 \\
\hline 11 & BN2 & 11 & 0.5625 \\
\hline 12 & BN5 & 12 & 0.5625 \\
\hline 13 & BN13 & 13 & 0.5625 \\
\hline 14 & BN12 & 14 & 0.5625 \\
\hline 15 & BN0 & 15 & 0.5625 \\
\hline 16 & BD2 & 16 & 0.5625 \\
\hline 17 & BD3 & 17 & 0.5625 \\
\hline 18 & BN10 & 18 & 0.5625 \\
\hline 19 & BD7 & 19 & 1.0 \\
\hline 20 & BN16 & 20 & 0.5625 \\
\hline 21 & BD8 & 21 & 1.0 \\
\hline & & & \\
\hline
\end{tabular}




\begin{tabular}{|c|c|c|c|}
\hline No & Node & Edge & $\begin{array}{c}\text { Closeness } \\
\text { Centrality }\end{array}$ \\
\hline$(1)$ & $(2)$ & $(3)$ & $(4)$ \\
\hline 22 & BD5 & 22 & 0.5625 \\
\hline 23 & BN1 & 23 & 0.5625 \\
\hline 24 & BN7 & 24 & 0.5625 \\
\hline 25 & BD9 & 25 & 1.0 \\
\hline 26 & BD10 & 26 & 1.0 \\
\hline 27 & BN6 & 27 & 0.5625 \\
\hline 28 & BD1 & 28 & 1.0 \\
\hline \hline
\end{tabular}

Sumber: SNA 09.1, 2016.

\section{b) Betweenes centrality.}

Betweennes Centrality menandai seberapa pentingnya node yang didasarkan pada jumlah banyaknya shortest path yang melaluinya.

Betweenness centrality digunakan untuk mengetahui bobot setiap node berdasar seberapa banyak node/lembaga dilalui oleh node-node lainya dalam sebuah graf berdasar jalur terpendeknya.

Perhitungan bobot betweenness centrality untuk setiap node dapat menggunakan rumus sebagai berikut;

Berikut tabulasi dari betweenes centrality antar stakeholder pengelola perbatasan di Kepulauan Riau;

\begin{tabular}{|c|c|c|c|}
\hline No & Node & Edge & $\begin{array}{c}\text { Betweenes } \\
\text { Centrality }\end{array}$ \\
\hline$(1)$ & $(2)$ & $(3)$ & $(4)$ \\
\hline 1 & BN8 & 1 & 0.0 \\
\hline 2 & BN14 & 2 & 0.0 \\
\hline 3 & BN11 & 3 & 0.0 \\
\hline 4 & BN17 & 4 & 0.0 \\
\hline 5 & BD6 & 5 & 0.10968660 \\
\hline
\end{tabular}

\begin{tabular}{|c|c|c|c|}
\hline No & Node & Edge & $\begin{array}{c}\text { Betweenes } \\
\text { Centrality }\end{array}$ \\
\hline (1) & (2) & (3) & (4) \\
\hline & & & 968660968 \\
\hline 6 & BN4 & 6 & 0.0 \\
\hline 7 & BD4 & 7 & 0.0 \\
\hline 8 & BN15 & 8 & 0.0 \\
\hline 9 & BN3 & 9 & 0.0 \\
\hline 10 & BN9 & 10 & 0.0 \\
\hline 11 & BN2 & 11 & 0.0 \\
\hline 12 & BN5 & 12 & 0.0 \\
\hline 13 & BN13 & 13 & 0.0 \\
\hline 14 & BN12 & 14 & 0.0 \\
\hline 15 & BN0 & 15 & 0.0 \\
\hline 16 & BD2 & 16 & 0.0 \\
\hline 17 & BD3 & 17 & 0.0 \\
\hline 18 & BN10 & 18 & 0.0 \\
\hline 19 & BD7 & 19 & $\begin{array}{l}0.10968660 \\
968660968\end{array}$ \\
\hline 20 & BN16 & 20 & 0.0 \\
\hline 21 & BD8 & 21 & $\begin{array}{l}0.10968660 \\
968660968\end{array}$ \\
\hline 22 & BD5 & 22 & 0.0 \\
\hline 23 & BN1 & 23 & 0.0 \\
\hline 24 & BN7 & 24 & 0.0 \\
\hline 25 & BD9 & 25 & $\begin{array}{l}0.10968660 \\
968660968\end{array}$ \\
\hline 26 & BD10 & 26 & $\begin{array}{l}0.10968660 \\
968660968\end{array}$ \\
\hline 27 & $\mathrm{BN} 6$ & 27 & 0.0 \\
\hline 28 & BD1 & 28 & $\begin{array}{l}0.10968660 \\
968660968\end{array}$ \\
\hline
\end{tabular}

Sumber: Data Olahan, 2016.

Sesama Kementrian yang menjadi anggota BNPP memiliki jarak antar node yang paling pendek $(0,0)$. Artinya bahwa tidak ada penghalang antar Kementrian atau Lembaga Non Kementrian dalam berkomunikasi. Maka apabila Presiden 
selaku kepala pemerintahan memberikan perintah langsung maka seluruh Kementrian dan lembaga Non Kementerian tersebut bisa langsung menjalin komunikasi tanpa ada penghubung diantaranya.

Berbeda dengan Lembaga ditingkat daerah yang diberi kode node (BD). Ketika mereka ingin berkomunikasi dengan Kementerian atau Lembaga nonKementerian yang terkait dengan urusan mereka maka mereka harus melalui prokoler dan tidak bisa langsung mengakses sumber informasi. Hal ini dibenarkan oleh Kepala Badan Pengelola Perbatasan Kabupaten Karimun dan Batam. Bahkan meskipun anggaran itu ada di kementerian atau Lembaga nonkementerian mereka harus membuat proposal usulan program yang diperlukan tersebut.

\section{PENUTUP}

Kepulauan Riau merupakan Provinsi yang berbatasan laut dengan 4 (empat) negara. Karena Kepulauan Riau memiliki perbatasan dengan negara-negara tetangga, maka pemerintah membentuk lembaga pengelola perbatasan. Bahkan dari 7 Kabupaten/Kota yang ada, 5 (lima) diantaranya memiliki lembaga pengelola perbatasan yang berguna mempermudah koordinasi dan komunikasi.
Dari penelitian yang dilakukan terkait dengan pengelolaan kawasan perbatasan antar negara di Kepulauan Riau didapati bahwa belum terjadi sinergi apalagi kolaborasi yang baik antara Badan Nasional Pengelola Perbatasan dengan Satuan Kerja Perangkat Daerah dimasing-masing Kabupaten/Kota. Terdapat beberapa hambatan yang menyebabkan kolaborasi antar Lembaga pengelola perbatasan tersebut belum terjadi jejaring sebagaimana yang diharapkan. Diantaranya adalah masih adanya ego sectoral. BNPP masih merasa sebagai bagian dari pemerintah pusat yang mengerti banyak hal terkait dengan pengelolaan perbatasan.

Disisi yang lain, SKPD lebih dekat dan merasa lebih memahami situasi dan kondisi yang terjadi disetiap waktu dan setiap kondisi di daerah. Kebutuhankebutuhan masyarakat di daerah perbatasan mereka lebih menguasai dan beranggapan bahwa mereka punya tawaran solusi yang diharapkan.

Hasil kajian ini memiliki implikasi teori terhadap konsep kolaborasi dalam tata kelola perbatasan laut, sebagai bahan masukan terhadap praktek tata kelola yang lebih baik kedepannya.

\section{DAFTAR PUSTAKA}

Baird, J., Plummer, R., \& Bodin, Ö. (2016). Collaborative governance for climate change adaptation in 
Canada: experimenting with adaptive co-management. Regional Environmental Change, 16(3). https://doi.org/10.1007/s10113015-0790-5

BNPP. (2011). Grand Design Pengelolaan Batas Wilayah Negara dan Kawasan Perbatasan Tahun 2011-2025.

Bodin, Ö., B. Crona, and H. Ernstson. 2006. Social networks in natural resource management: What is there to learn from a structural perspective? Ecology and Society.

Creswell, J. W. (n.d.). Research Design Qualitative, Quantitative, and Mixed Methods Approachces.

D. K. Kular, R. Menezes, and E. Ribeiro, "Using network analysis to understand the relation between cuisine and culture," Proc. 2011 IEEE

1st Int. Netw. Sci. Work. NSW 2011, pp. 38-45, 2011

Marsetio. (2014). SEA POWER INDONESIA.pdf (p. 149).

Rencana Pembangunan Jangka Menengah Daerah Provinsi kepulauan Riiau tahun 2010-2015, hal II-1

Siv Vangen and Chris Huxham, Enacting Leadership for Collaborative Advantage: Dilemmas of Ideology and Pragmatism in the Activities of Partnership Managers, British Journal of Management, Vol. 14, S61-S76
Sudjana, Nana. 2004. Dasar-dasar Proses Belajar Mengajar. Bandung :Sinar BaruAlgensido Offset

Yuliani, Irma. Santosa, Paulus Insap dan Setiawan, Noor Akhmad, 2015. Analisis Jejaring Media Sosial untuk Pemetaan pada Komunitas Online, disampaikan dalam Seminar Nasional Aplikasi Teknologi Informasi (SNATi) Yogyakarta, 6 Juni 2015, G14-G17 ISSN: 1907 5022

http://kepri.antaranews.com/berita/26 496/bc-gagalkan-penyelundupankamera-rp6-miliar

http://www.tribunnews.com/regional/ 2012/12/24/bc-tanjungpinangbatalkan-penyelundupan-34-kgheroin

http://jurnalintelijen.id/news-53101tni-al-gagalkan-perompakan-diperairan-kepulauan-riau.html http://jurnalintelijen.id/news-53101tni-al-gagalkan-perompakan-diperairan-kepulauan-riau.html http://batam.tribunnews.com/2013/01 L2/bajak-laut-kuras-solar-danpermium-di-perairan-moro-kepri 